\title{
Family-level leaf nitrogen and phosphorus stoichiometry of global terrestrial plants
}

Tian, Di ; Yan, Zhengbing ; Ma, Suhui ; Ding, Yuehong ; Luo, Yongkai ; Chen, Yahan ; Du, Enzai ; Han, Wenxuan ; Kovacs, Emoke Dalma ; Shen, Haihua ; Hu, Huifeng ; Kattge, Jens ; Schmid, Bernhard ; Fang, Jingyun

\begin{abstract}
Leaf nitrogen (N) and phosphorus (P) concentrations are critical for photosynthesis, growth, reproduction and other ecological processes of plants. Previous studies on large-scale biogeographic patterns of leaf $\mathrm{N}$ and $\mathrm{P}$ stoichiometric relationships were mostly conducted using data pooled across taxa, while family/genus-level analyses are rarely reported. Here, we examined global patterns of familyspecific leaf $\mathrm{N}$ and $\mathrm{P}$ stoichiometry using a global data set of 12,716 paired leaf $\mathrm{N}$ and $\mathrm{P}$ records which includes 204 families, 1,305 genera, and 3,420 species. After determining the minimum size of samples (i.e., 35 records), we analyzed leaf $\mathrm{N}$ and $\mathrm{P}$ concentrations, $\mathrm{N}: \mathrm{P}$ ratios and $\mathrm{N} \mathrm{P}$ scaling relationships of plants for 62 families with 11,440 records. The numeric values of leaf $\mathrm{N}$ and $\mathrm{P}$ stoichiometry varied significantly across families and showed diverse trends along gradients of mean annual temperature (MAT) and mean annual precipitation (MAP). The leaf $\mathrm{N}$ and $\mathrm{P}$ concentrations and N:P ratios of 62 families ranged from 6.11 to $30.30 \mathrm{mg} \mathrm{g}-1,0.27$ to $2.17 \mathrm{mg} \mathrm{g}-1$, and 10.20 to 35.40 , respectively. Approximately $1 / 3-1 / 2$ of the families (22-35 of 62 ) showed a decrease in leaf $\mathrm{N}$ and $\mathrm{P}$ concentrations and $\mathrm{N}: \mathrm{P}$ ratios with increasing MAT or MAP, while the remainder either did not show a significant trend or presented the opposite pattern. Family-specific leaf N P scaling exponents did not converge to a certain empirical value, with a range of $0.307-0.991$ for 54 out of 62 families which indicated a significant N P scaling relationship. Our results for the first time revealed large variation in the family-level leaf $\mathrm{N}$ and $\mathrm{P}$ stoichiometry of global terrestrial plants and that the stoichiometric relationships for at least one-third of the families were not consistent with the global trends reported previously. The numeric values of the family-specific leaf $\mathrm{N}$ and $\mathrm{P}$ stoichiometry documented in the current study provide critical synthetic parameters for biogeographic modeling and for further studies on the physiological and ecological mechanisms underlying the nutrient use strategies of plants from different phylogenetic taxa.
\end{abstract}

DOI: https://doi.org/10.1007/s11427-019-9584-1

Posted at the Zurich Open Repository and Archive, University of Zurich

ZORA URL: https://doi.org/10.5167/uzh-180658

Journal Article

Accepted Version

Originally published at:

Tian, Di; Yan, Zhengbing; Ma, Suhui; Ding, Yuehong; Luo, Yongkai; Chen, Yahan; Du, Enzai; Han, Wenxuan; Kovacs, Emoke Dalma; Shen, Haihua; Hu, Huifeng; Kattge, Jens; Schmid, Bernhard; Fang, Jingyun (2019). Family-level leaf nitrogen and phosphorus stoichiometry of global terrestrial plants. Science China. Life sciences, 62(8):1047-1057. 
DOI: https://doi.org/10.1007/s11427-019-9584-1 
1 Family-level leaf nitrogen and phosphorus stoichiometry of global terrestrial

2 plants

4 Di Tian ${ }^{1}$, Zhengbing Yan $^{2}$, Suhui $\mathrm{Ma}^{2}$, Yuehong Ding ${ }^{1}$, Yongkai $\mathrm{Luo}^{3}$, Enzai $\mathrm{Du}^{3}$, Wenxuan

$5 \mathrm{Han}^{4}$, Wenxuan Han ${ }^{5}$, Emoke Dalma Kavacs ${ }^{6}$, Haihua Shen ${ }^{3}$, Huifeng $\mathrm{Hu}^{3}$, Jens Kattge ${ }^{7}$,

6 Bernhard Schmid ${ }^{8}$, Jingyun Fang ${ }^{2 *}$

7

8 1College of Life Sciences, Capital Normal University, Beijing 100048, China;

9 2Institute of Ecology, College of Urban and Environmental Sciences, and Key Laboratory for

10 Earth Surface Processes of the Ministry of

11 Education, Peking University, Beijing 100871, China;

12 3State Key Laboratory of Vegetation and Environmental Change, Institute of Botany, Chinese

13 Academy of Sciences, Beijing 100093, China;

14 4College of Resources Science \& Technology, and State Key Laboratory of Earth Surface

15 Processes and Resource Ecology, Beijing Normal

16 University, Beijing 100875, China;

17 5Key Laboratory of Plant-Soil Interactions, Ministry of Education, College of Resources and

18 Environmental Sciences, China Agricultural

19 University, Beijing 100193, China;

20 6National Institute for Research and Development in Optoelectronics INCDO-INOE 2000,

21 Research Institute for Analytical Instrumentation

22 ICIA subsidiary, Cluj-Napoca 400293, Romania;

23 7Max-Planck-Institute for Biogeochemistry, Jena 07745, Germany;

248 Department of Evolutionary Biology and Environmental Studies, University of Zurich, Zurich

258057 , Switzerland

26

27

*Corresponding author:

28 Jingyun Fang, Ph.D.

29 Professor of Ecology

30 Department of Ecology

31 Peking University 
32 Beijing 100871, China

33 Tel/Fax: +86-10-6275 6560

34 E-mail: jyfang@urban.pku.edu.cn 


\section{Abstract:}

Leaf nitrogen $(\mathrm{N})$ and phosphorus $(\mathrm{P})$ concentrations are critical for photosynthesis, growth, reproduction and other ecologicalprocesses of plants. Previous studies on large-scale biogeographic patterns of leaf $\mathrm{N}$ and $\mathrm{P}$ stoichiometric relationships weremostly conducted using data pooled across taxa, while family/genus-level analyses are rarely reported. Here, we examined globalpatterns of family-specific leaf $\mathrm{N}$ and $\mathrm{P}$ stoichiometry using a global data set of 12,716 paired leaf $\mathrm{N}$ and $\mathrm{P}$ records whichincludes 204 families, 1,305 genera, and 3,420 species. After determining the minimum size of samples (i.e., 35 records), weanalyzed leaf $\mathrm{N}$ and $\mathrm{P}$ concentrations, $\mathrm{N}: \mathrm{P}$ ratios and $\mathrm{N} \sim \mathrm{P}$ scaling relationships of plants for 62 families with 11,440 records. Thenumeric values of leaf $\mathrm{N}$ and $\mathrm{P}$ stoichiometry varied significantly across families and showed diverse trends along gradients ofmean annual temperature (MAT) and mean annual precipitation (MAP). The leaf $\mathrm{N}$ and $\mathrm{P}$ concentrations and N:P ratios of 62 families ranged from 6.11 to $30.30 \mathrm{mg} \mathrm{g-1,} 0.27$ to $2.17 \mathrm{mg} \mathrm{g-1}$, and 10.20 to 35.40 , respectively. Approximately $1 / 3-1 / 2$ of thefamilies (22-35 of 62) showed a decrease in leaf $\mathrm{N}$ and $\mathrm{P}$ concentrations and N:P ratios with increasing MAT or MAP, while theremainder either did not show a significant trend or presented the opposite pattern. Family-specific leaf N P scaling exponentsdid not converge to a certain empirical value, with a range of $0.307-0.991$ for 54 out of 62 families which indicated a significantN P scaling relationship. Our results for the first time revealed large variation in the family-level leaf $\mathrm{N}$ and $\mathrm{P}$ stoichiometry ofglobal terrestrial plants and that the stoichiometric relationships for at least one-third of the families were not consistent with theglobal trends reported previously. The numeric values of the family-specific leaf $\mathrm{N}$ and $\mathrm{P}$ stoichiometry documented in thecurrent study provide critical synthetic parameters for biogeographic modeling and for further studies on the physiological andecological mechanisms underlying the nutrient use strategies of plants from different phylogenetic taxa.

\section{INTRODUCTION}

Nitrogen $(\mathrm{N})$ and phosphorus $(\mathrm{P})$ are essential components of basic cell structure of higher plants, especially playing pivotal roles in the synthesis and transformation of protein and nucleic acids (Garten, 1976). N and P concentrations and their stoichiometric balances of leaves, the fundamental tissues for photosynthesis of higher plants, determine the whole plants' photosynthate, growth, reproduction and other functional traits, and further influence soil-plant nutrient cycling, community biodiversity dynamics, vegetation productivity and ecosystem succession (Asner et al., 1997; Niklas et al., 2005; Reich et al., 2009; Sullivan et al., 2014; Tang et al., 2018). 
As key properties of leaf economic spectrum (i.e. LES), leaf $\mathrm{N}$ and $\mathrm{P}$ concentrations generally show strong correlation in their biochemical functioning (Wright et al., 2004; Ågren, 2008). Previous studies have figured out the broad-scale leaf $\mathrm{N}$ and $\mathrm{P}$ stoichiometric patterns and proposed several hypothetical theories through their exploration of nutrient stoichiometry from regional to global scales. For example, Reich et al. (2004) generalized the global patterns of higher plant leaf $\mathrm{N}$ and $\mathrm{P}$ stoichiometry across latitudinal and temperature gradients (e.g. leaf $\mathrm{N}$ and $\mathrm{P}$ increase from tropics to the midlatitudes and keep stable or decrease at higher latitudes, and $\mathrm{N}: \mathrm{P}$ ratios increases with mean temperature), and further tested the temperature-plant physiological hypotheses and biogeochemical hypotheses. Using data of national terrestrial plants, Han et al. (2005) reported that the overall leaf N:P ratios of China's flora was higher than the global averages even though leaf $\mathrm{N}$ and $\mathrm{P}$ showed consistent trends along latitudinal gradients, which was probably a result of limited soil $\mathrm{P}$ availability in China according to the soil substrate age hypothesis (Carnicer et al., 2014). At regional level, specific species (e.g. Picea abies and Artemisa species) also showed divergent geographic patterns along longitudinal (i.e. MAP), latitudinal (i.e. MAT) and altitudinal gradients (Kang et al., 2011; Yang et al., 2015). In terms of different growth forms, the relative growth rate hypothesis (i.e. GRH) has attracted tremendous interest and been prevalently used in explaining the variations of elemental stoichiometry across growth forms (Chapin et al., 1986; Sterner and Elser, 2002; Tian et al., 2018). For example, woody plants, compared to herbaceous plants, generally show lower $\mathrm{N}$ and $\mathrm{P}$ concentrations for their slower growth rates and effective physiological strategies for nutrient conservation (e.g. improving nutrient use efficiency through their intrinsic nutrient resorption and transformation strategies) (Elser, et al., 2010; McGroddy et al., 2008; Brant and Chen, 2015).

Leaf $\mathrm{N}: \mathrm{P}$ ratios and $\mathrm{N} \sim \mathrm{P}$ scaling relationships are two indicators of the coupling relationships between leaf $\mathrm{N}$ and $\mathrm{P}$ concentrations. The later one can be quantified via a stoichiometric scaling relationship described by a power function as $\mathrm{N}=\beta \mathrm{P}^{\alpha}$, where $\alpha$ and $\beta$ represent the scaling exponent and the intercept (i.e. normalization constant) of the log-log linear leaf $\mathrm{N}$ concentration vs. P concentration regression curve, respectively (Wright et al., 2004; Niklas, 2006; Tian et al., 2018). When $\alpha$ equals to 1 , the numeric value of $\beta$ is leaf $\mathrm{N}: \mathrm{P}$ ratio because of the isometric scaling relationship. Alternatively, $\alpha<1$ indicates a faster change of leaf $\mathrm{P}$ concentration in proportion to leaf $\mathrm{N}$ concentration while $\alpha>1$ indicates the opposite case (Niklas et al., 2005; Kerkhoff et al., 2006; McGroddy et al., 2008). 
In various ecosystems, leaf $\mathrm{N}: \mathrm{P}$ ratios were widely interpreted as indicators of environmental $\mathrm{N}$ and P relative availabilities. Despite their shortages and potential high risks (Yan et al., 2017), empirical values of leaf $\mathrm{N}: \mathrm{P}$ ratios proposed in previous studies at community or vegetation levels have been commonly used as thresholds for determining $\mathrm{N}$ or P deficiency (e.g. N:P ratios $<14$ and $>16$ or $<10$ and $>20$ were used as thresholds for assessing $\mathrm{N}$ and $\mathrm{P}$ limitation, respectively) (Koerselman and Meuleman, 1996; Güsewell, 2004). Leaf N P scaling relationships were also interpreted as plants' physiological strategies resulted from their evolutionary adaptation to environmental nutrient availabilities although the underlying mechanisms remains unclear. For example, the 2/3- and 3/4-power laws obtained from pooled data have been used to ecological theories and prediction models as important plant functional traits and parameters (e.g. biogeochemical models; Carbon, N and P cycling models; Nutrientsvegetation productivity prediction models; The relative growth rate hypothesis and metabolic models; Stoichiometric homeostasis hypothesis; Metabolic scaling theory) (Wright et al., 2005; Allen and Gillooly, 2009; Elser et al., 2010; Carnicer et al., 2014; Tang et al., 2018).

Overall, previous studies were mainly focused on the large-scale patterns of leaf $\mathrm{N}$ and $\mathrm{P}$ stoichiometric relationships across geographic gradients in relation to climatic and environmental factors (Wright et al., 2004; Reich et al., 2004; Chen et al., 2013; Hao et al., 2015; Zhang et al., 2018). However, whether the general leaf $\mathrm{N}$ and $\mathrm{P}$ stoichiometric relationship hold at more specific scales and could be used as constant plant trait in related models has attracted researchers' attention (Messier et al. 2016; Tian et al., 2018). For example, our recent study has demonstrated that leaf $\mathrm{N}$ and $\mathrm{P}$ scaling exponent vary significantly across different functional groups, latitudinal zones, ecological biomes and specific sites (Tian et al., 2018), which resonated with Messier et al. (2016)'s argument that LES may not hold or show large variation at smaller scales.

Likewise, phylogenetic taxa represent a kind of scale. Some researchers have reported the phylogenetic signals in leaf $\mathrm{N}$ and P stoichiometry (e.g. Thompson et al., 1997; Kerkhoff et al., 2006; Peñuelas et al., 2010), especially at family- and subfamily-levels (Zhang et al., 2012; Hao et al., 2015). Hence, it provides us an alternative approach to verify previous theories and hypothesis of leaf $\mathrm{N}$ and $\mathrm{P}$ stoichiometric relationships on the family-levels (White et al., 2012; Zhang et al., 2012), which also has possibilities to fulfill the considerable requirements for detail parameters in plant physiological and ecosystem functioning prediction models (Sterner 
and Elser, 2002; Osnas et al., 2013; Tang et al., 2018). However, no comprehensive study to date has comprehensively conducted considering leaf $\mathrm{N}$ and $\mathrm{P}$ stochiometric relationships on family-levels.

Our study aims to fill these gaps by providing to date the largest global leaf $\mathrm{N}$ and $\mathrm{P}$ concentration dataset and analyzing leaf $\mathrm{N}$ and $\mathrm{P}$ stoichiometric relationships on family-level of higher plants. To do this, we calculated leaf $\mathrm{N}$ and $\mathrm{P}$ stoichiometric values of specific families and examined their relationships with climatic factors. Our objectives are to test the following questions: (1) how higher plants leaf $\mathrm{N}$ and $\mathrm{P}$ stochiometric relationships change on the familylevels ? (2) how their geographical patterns change along MAT and MAP ? (3) do leaf N P scaling exponents of specific families converge to an empirical value (i.e. whether the globallevel leaf $\mathrm{N} \sim \mathrm{P}$ scaling exponent hold on the family-level)?

\section{MATERIALS AND METHODS}

\subsection{Dataset}

We established a global data set of paired leaf $\mathrm{N}$ and $\mathrm{P}$ records following strict principles. Records of paired $\mathrm{N}$ and $\mathrm{P}$ concentrations of green leaves with detailed location information were compiled in the data set. Unpaired and mismatched leaf N-P records, records without site information, plants cultivated in greenhouse or plantations and duplicated records were directly excluded. Finally, 4,212 records from the TRY data set (https://www.try-db.org) (Kattge et al., 2011) and 8,509 records from previous studies and our own field sampling were adopted to the data set (Tian et al., 2018). All the records of plant samples were collected in their growing season and leaf $\mathrm{N}$ and $\mathrm{P}$ concentration were detected on the mass unit. The phylogenetic taxa information of the total 12,721 records in our data set were then identified using Flora of China (http://frps.eflora.cn/), including 204 families, 1,305 genus and 3420 species.

\subsection{Statistic analysis}

To avoid potential error risks induced from the sample sizes of specific families, we firstly used Monte Carlo methods and randomly sampled certain numbers of pairwise leaf $\mathrm{N}$ and $\mathrm{P}$ records in our data set from 5 to 10,000 at 1000 iterations, respectively. We then calculated the statistics including geometric means, ranges, coefficient of variance (CV), standard error (SE) of leaf $\mathrm{N}$ and $\mathrm{P}$ concentrations, $\mathrm{N}: \mathrm{P}$ ratios and $\mathrm{N} \sim \mathrm{P}$ scaling relationships based on the randomly sampled 
171 records. During these analysis, we used the original values of the individual paired records. For 172 the statistics of $\mathrm{N} \sim \mathrm{P}$ scaling relationships, we used the reduced major axis (RMA) regression 173 (Warton et al., 2006) after $\log 10$-transforming the original values of $\mathrm{N}$ and $\mathrm{P}$ concentration. 174 Additionally, we used a likelihood ratio test to evaluate the differences between RMA 175 regression exponents of each family and the empirical values (i.e. 2/3 and 3/4).

177 During the performing of Monte Carlo sampling, we found that the variation of leaf $\mathrm{N}$ and $\mathrm{P}$ 178 stoichiometric statistics became smaller with the increase of sample size. When the sample sizes 179 were more than 35 , the CVs of their leaf $\mathrm{N}$ and $\mathrm{P}$ concentrations and $\mathrm{N}: \mathrm{P}$ ratios were below $10 \%$ 180 (Table S1, Figures S1 and S2). Similarly, the frequencies of significant N P scaling 181 relationships in 1000 iterations increased with sample size and were higher than $90 \%$ with CV 182 values below 15\% when the sample sizes were more than 35 (Table S2, Figure S3a and 3b). 183 Hence, we chose all the families with at least 35 individual records from the dataset for further 184 statistical analysis. Additionally, we explored the biogeographic patterns of leaf $\mathrm{N}$ and $\mathrm{P}$ 185 stoichiometry of each family along MAT and MAP, respectively, using a linear model. The data 186 of MAT and MAP were extracted from WorldClim (http://www.worldclim.org/). All statistical analyses were performed in the R 3.5.1 software (R core Team, 2018).

\section{RESULTS}

\subsection{Leaf $N$ and $P$ stoichiometry on family-level}

There were 62 families with at least 35 individual records in our dataset. Their geometric means of $\mathrm{N}$ and $\mathrm{P}$ concentrations and $\mathrm{N}: \mathrm{P}$ ratios ranged from 6.11 to $30.30 \mathrm{mg} \mathrm{g}^{-1}$, from 0.27 to 2.17 $\mathrm{mg} \mathrm{g}^{-1}$, from 10.20 to 35.40 , respectively (Table 1 ).

202

203 Comparatively, leaf N concentrations of Rutaceae, Chenopodiaceae, Ulmaceae, Liliaceae, 204 Umbelliferae, Tiliaceae, Ranunculaceae, Leguminosae, Polygonaceae, Zygophyllaceae and 
Elaeagnaceae were high (i.e. from 23.18 to $30.30 \mathrm{mg} \mathrm{g}^{-1}$ ). Leaf P concentrations of Labiatae,

206 Salicaceae, Liliaceae, Tiliaceae, Aceraceae, Ranunculaceae, Polygonaceae and Umbelliferae 207 were high (i.e. from 1.80 to $2.12 \mathrm{mg} \mathrm{g}^{-1}$ ).

We additionally found that leaf $\mathrm{N}: \mathrm{P}$ ratios of Cupressaceae, Pinaceae, Plantaginaceae, 210 Umbelliferae, Compositae, Salicaceae, Aceraceae and Labiatae were low (i.e. from 10.5 to 211 12.2), while the N:P ratios of Symplocaceae, Melastomataceae, Proteaceae, Leguminosae, 212 Burseraceae, Gleicheniaceae, Sapotaceae, Lecythidaceae and Myricaceae were high (i.e. from 21322.2 to 35.4$)$.

\subsection{Biogeographic patterns of leaf $\mathrm{N}$ and $\mathrm{P}$ stoichiometry on family-level} 62 families showed large variation in their location distribution. Their $\mathrm{N}$ and $\mathrm{P}$ concentrations and N:P ratios also showed divergent biogeographic patterns along MAT and MAP, respectively (Table S3, Figure 1).

Specifically, in terms of leaf $\mathrm{N}$ concentrations, 33 families declined and 4 families increased with increasing MAT, 22 families declined and 8 families increased with increasing MAP, while 22 families showed no significant change with MAT and MAP. For leaf P concentrations, 29 families declined and 3 families increased with increasing MAT, 35 families declined and 7 families increased with increasing MAP, whereas 30 and 20 families showed no significant change with MAT and MAP, respectively. For leaf N:P ratios, 29 families increased and 3 families decreased with increasing MAT, 24 families declined and 2 families increased with increasing MAP, whereas 30 and 36 families showed no significant change with MAT and MAP, respectively.

\subsection{Leaf $\mathrm{N} \sim \mathrm{P}$ scaling relationship on family-level}

23154 of the 62 families showed significant leaf $\mathrm{N}$ and P scaling relationships (Tables 2 and S3) 232 and their scaling exponents ranged from 0.307 to 0.991 with a geometric mean of 0.633 (Table 233 2, Figure 2), while the other 8 families' leaf $\mathrm{N}$ and $\mathrm{P}$ concentrations were not statistically 234 significantly correlated.

Moreover, when comparing 54 families' leaf N P scaling exponents with empirical numeric values (i.e. $2 / 3$ and 3/4), 23 families showed significant difference with 2/3 (i.e. 13 families < $2 / 3$ and 10 families $>2 / 3$ ) whereas 31 families showed no significant difference with $2 / 3$. 
Similarly, 30 families were significantly different from 3/4 (i.e. 27 families $<3 / 4$ and 3 families $>$

240 3/4) while 24 families showed no significant difference with 3/4. Meanwhile, 17 families' leaf

$241 \mathrm{~N} \sim \mathrm{P}$ scaling exponents covered both $2 / 3$ and $3 / 4$ (Table 2).

\section{DISCUSSION}

\subsection{Variations in leaf $N$ and $P$ stoichiometry on family-level}

Leaf $\mathrm{N}$ and $\mathrm{P}$ concentrations and their stoichiometric relationships closely correlated with plant growth and performance (Garten, 1976; Nielsen et al., 1996; Elser et al., 2000, 2010). Variation in leaf $\mathrm{N}$ and $\mathrm{P}$ concentrations on family-level reflected the joint influences of interior genetic properties and extrinsic environmental factors (Kerkhoff et al., 2006; Ågren and Weih, 2012). The former included leaf morphology, leaf lifespan, leaf age, nutrient storage and allocation among tissues, plant growth rate, stoichiometric homeostasis and plasticity and other physiological processes (Chapin et al., 1986; Elser et al., 2010; Sardans et al., 2012; Sistla et al., 2015). The latter mainly covered climatic conditions, soil physiochemical properties and nutrient availabilities (Vitousek and Turner, 1995; Zhang et al., 2012; Hao et al., 2015).

As a result of divergent nutrient use strategies and specific leaf structures and metabolic functions, the variations in leaf $\mathrm{N}$ and $\mathrm{P}$ stoichiometry on family-level revealed plants' adaptation to biotic and abiotic factors during their evolution (Güsewell, 2004; Sardans and Peñuelas, 2014; Delgado et al., 2014; Sardans et al., 2016). For example, leaf N and P concentrations of Proteaceae, Gleicheniaceae and Myrtaceae families were comparatively low with high N:P ratios among 62 families. Gymnosperms including Cupressaceae and Pinaceae families showed low $\mathrm{N}$ concentrations and $\mathrm{N}: \mathrm{P}$ ratios. These results were consistent with previous studies on regional scales (e.g. Fould, 1993; Thompson et al., 1997). In general, as most plants of these families were oligotrophic pioneer species in the early stage of community succession in nutrient-poor soils, they developed high tolerance to environmental stress and effective nutrient use strategies (Page et al., 2002; Lamber et al., 2008; Fujita et al., 2013; Sardans et al., 2016). Especially, the Proteaceae family that distributed in severe P limited environment evolved adaptive structures and functions, such as enhanced efficiencies of $\mathrm{P}$ resorption, $\mathrm{P}$ transformation and reallocation across different tissues, delayed leaf senescence and special root structures with dense clusters of rootlets and root hair (Delgado et al., 2014; Lambers et al., 2015). In contrast, families of Elaeagnaceae, Leguminosae and Ulmaceae showed high $\mathrm{N}$ concentrations partly owing to their symbiotic $\mathrm{N}$-fixing microorganisms (Torrey, 
1978). Moreover, our finding that leaf $\mathrm{N}$ concentrations of Elaeagnaceae were higher than

274 Leguminosae renovated conceptual understandings and provided new reference for the study

275 on plant-microorganism mutualistic symbiosis.

277 The variations in leaf $\mathrm{N}$ and $\mathrm{P}$ stoichiometry on family-level support previous reports that leaf

$278 \mathrm{~N}$ and $\mathrm{P}$ concentrations and N:P ratios differ significantly across life forms and the GRH

279 hypothesis: small-size fast-growing herbaceous plants have higher $\mathrm{N}$ and $\mathrm{P}$ concentrations and

280 lower N:P ratios than large-size slow-growing woodies (Sterner and Elser 2002; Wright et al.,

281 2005; Han et al., 2011; Tian et al., 2018). For example, families of Polygonaceae,

282 Zygophyllaceae, Ranunculaceae and Umbelliferae are mainly herbaceous plants, subshrubs and

283 shrubs, with higher leaf $\mathrm{N}$ and $\mathrm{P}$ concentrations. Comparatively, families of Myrtaceae,

284 Theaceae, Symplocaceae and Ericaceae with predominately woody species have lower leaf $\mathrm{N}$

285 and $\mathrm{P}$ concentrations.

In fact, our results are also in agreement with the biogeochemical niche hypothesis which attributes the differences in plants' key structural, physiological and chemical foliar properties across taxonomic groups to their specific biogeochemical niches (Peñelas et al., 2010). On the global scale, boreal and temperate biomes are often demonstrated to be N-limited, while tropical ecosystems are P-limited. Hence, leaf $\mathrm{N}$ and $\mathrm{P}$ stoichiometry of plants distributed in these biomes might be directly influenced by soil nutrient availabilities (Vitousek and Farrington, 1997; Carnicer e al., 2014; Deng et al., 2017). For example, the widespread families of Cupressaceae and Pinaceae in boreal and temperate biomes have low leaf $\mathrm{N}$ concentration but comparatively high $\mathrm{P}$ concentration, which is a result of the cold environment and soil $\mathrm{N}$ limitation. The high leaf $\mathrm{P}$ concentrations benefit them for cold resistance and fast growth during their short growth periods (Chapin et al., 1986). On the same rationale, as a majority of Myricaceae, Myrtaceae, Lecythidaceae, Sapotaceae, Symplocaceae, Melastomataceae,

299 Theaceae, Myrsinaceae and Burseraceae families are evergreen woody plants distributing in 300 tropical and subtropical areas, their leaf P concentrations are consequently quite low (i.e. all < $\left.301 \quad 1.00 \mathrm{mg} \mathrm{g}^{-1}\right)$.

302

\subsection{Biogeographic pattern of leaf $N$ and $P$ stoichiometry on family-level} Previous explorations of leaf $\mathrm{N}$ and $\mathrm{P}$ stoichiometry at regional and global scales have reported the general biogeographic pattern that leaf $\mathrm{N}$ and $\mathrm{P}$ concentrations decrease but $\mathrm{N}: \mathrm{P}$ ratios increase with increasing MAT (Reich and Oleksyn, 2004; Han et al., 2005, 2011; Zhang et al., 
2012). Several studies have tried to further quantify the evolutionary and environmental control on variations of leaf element stoichiometry (Watanabe et al., 2007; Zhang et al., 2012; Yang et al., 2017). For example, Watanabe et al. (2007) addressed that over $25 \%$ of the total variation in leaf element composition could be explained by family level taxonomy and the remaining variations could be substantially assigned to climatic factors, soil conditions, sampling techniques and differences between species within families. In addition, plant taxonomy largely influences biogeographic patterns of leaf $\mathrm{N}$ and $\mathrm{P}$ stoichiometry across environmental gradients (i.e. latitude, longitude, altitude, MAT, MAP) (He et al., 2010; Chen et al., 2013; Zhang et al., 2012; Yang et al., 2015), which might imply that leaf $\mathrm{N}$ and $\mathrm{P}$ stoichiometry is phylogenetically conserved (Sardans and Peñuelas, 2014; Hao et al., 2015; Yang et al., 2015; Sardans et al., 2016). Although our focus in the current study is not on detecting the phylogenetic signal and the convergence of leaf $\mathrm{N}$ and $\mathrm{P}$ stoichiometry on family-level, our results correspondingly revel that leaf $\mathrm{N}$ and $\mathrm{P}$ concentrations and $\mathrm{N}: \mathrm{P}$ ratios differ significantly (Table 1) and show divergent trends along MAT and MAP across families (Figure 1).

For leaf $\mathrm{N}$ concentrations, approximately a half families (i.e. 33 of 62 families) declined with increasing MAT and less than 1/3 families (i.e. 22 of 62 families) decreased with increasing MAP, which were in consistent with the general patterns of pooled data (Reich and Oleksyn, 2004; Han et al., 2005). However, the other 29 and 30 families in our dataset showed the opposite trends or no significant change along MAT and MAP, respectively. For leaf P, more than a half families (35 of 62 families) declined with increasing MAP, whereas approximately a half families (30 of 62 families) did not change with MAT. These results resonated with previous generalization on reginal scales that MAT and MAP showed comparatively stronger effects on leaf $\mathrm{N}$ and $\mathrm{P}$ concentrations, respectively. We additionally attributed some families' lack of pattern along MAT and MAP to their smaller geographic distributions and environmental gradients, such as Symplocaceae, Sapindaceae and Gleicheniaceae families widespread in tropical and subtropical areas (Table S3). Furthermore, the nonsignificant correlation might also imply that leaf $\mathrm{N}$ and $\mathrm{P}$ stoichiometry of these families are highly conserved with low stoichiometric plasticity due to their narrow geographical and biogeochemical niches (Yu et al., 2010, 2015; Sardans et al., 2016; Guo et al., 2017).

In particular, we amazedly recognized that leaf $\mathrm{N}: \mathrm{P}$ ratios of 30 and 36 families showed no trends along MAT and MAP, respectively, which was inconsistent with the general pattern that global leaf N:P ratios increased with increasing MAT (Reich and Oleksyn, 2004; Kerkhoff et 
al., 2005; Zhang et al., 2018). However, our results resonated with previous studies conducted by Han et al. (2005), Zhang et al. (2012) and Yang et al. (2015). Although it's an open questions whether phylogeny (or genotype) is more important than environment when researchers seek to disentangle the effects of genotypic and environmental factors on leaf $\mathrm{N}$ and $\mathrm{P}$ stoichiometry, our study highlight the importance and necessity of considering phylogenetic and taxonomic information in plant stoichiometry studies.

\subsection{Inconstant leaf $N \sim P$ scaling relationships on family-level}

Our results showed that leaf $\mathrm{N}$ and $\mathrm{P}$ concentrations of most higher plants coupled significantly with scaling exponents ranging from 0.307 to 0.991 , which reinforced the inconstant leaf $\mathrm{N} \sim \mathrm{P}$ scaling relationships proposed by Tian et al. (2018) from family-level study. Moreover, the specific exponents of family-level leaf $\mathrm{N} \sim \mathrm{P}$ scaling relationships varied substantially with previous overall results (e.g. Wright et al., 2004; Niklas \& Cobb 2005; Niklas 2006; Kerkhoff et al., 2006; McGroddy et al., 2008; Reich et al., 2010; Zhao et al., 2016). In addition, the specific exponents of family-level leaf $\mathrm{N} \sim \mathrm{P}$ scaling relationships have no correlation with their sample sizes (Figure S4 a and b), implying that family-level leaf N P scaling exponents might not consequentially converge to a certain value with their increasing sample sizes.

As a part of leaf economic spectrum (Wright et al., 2004), 'conserved' leaf N P scaling relationship is the key determining its practical application. For example, Price et al. (2014) examined the 'invariance' of LES and concluded that all LES traits approached invariance within and between plant lifeforms, taxonomic groups and biomes. However, our results displayed inconsistency that leaf $\mathrm{N} \sim \mathrm{P}$ scaling relationship varied significantly even in the same life from. For example, leaf N P scaling exponents of Myricaceae and Tamaricaceae were the highest (i.e. 0.965) and the lowest (i.e. 0.307), respectively, among 62 families, even though they are both in woody groups.

Kerkhoff et al. (2006) ascribed their find of strong phylogenetic signals and similar scaling relationships of leaf $\mathrm{N}$ and $\mathrm{P}$ concentrations to the influences of both evolutionary history and environmental molding. Nevertheless, our results presented large variations of leaf $\mathrm{N}$ and $\mathrm{P}$ stoichiometry across different families of higher plants, reasserting our recent statement that the canonical numerical value of global leaf $\mathrm{N} \sim \mathrm{P}$ scaling exponent might be a result of pooled data analysis which hides or neglects biologically and ecologically significant variations (Tian et al., 2018). Actually, no canonical leaf $\mathrm{N} \sim \mathrm{P}$ scaling relationship probably hold true across all 
375 plant lineages. Here, for pooled data, the mutual offsets among different families might also

376 produce a certain numeric value that misinterpret their inherent stoichiometric relationships.

377 For example, as illustrated in Figure S4 a and b, leaf N P scaling exponent generally, but not

378 all (e.g. Compositae), approached $2 / 3$ for families with large sample sizes (e.g. Leguminosae,

379 Gramineae). Hence, it remains difficult to distinguish whether the 2/3-power N P scaling

380 relationship is a result of the differences among species and individuals within the same family

381 or the true stoichiometric pattern of the family? Clearly, statistic analysis from pooled data

382 could not bring out an irrefutable truth.

383

384

385

386

387

388

389

390

391

392

393

394

395

396

397

ACKNOWLEDGEMENTS

398

399

We would like to thank Yongkai Luo, Yahan Chen, Zhiyao Tang, Wengjing Fang, Ming Ouyang,

400 Yaoqi Li, Hanyue Huang, Bernhard Schmid and Shaopeng Wang for their helpful suggestions

401 for data collection and analysis. We appreciate the researchers who contributed their available data of leaf $\mathrm{N}$ and $\mathrm{P}$ content to the global TRY database.

403

404

\section{FUNDING}

405 This work was supported by National Natural Science Foundation of China [31800397] and the TRY initiative on plant traits (http://www.try-db.org). The TRY database is hosted at the Max Planck Institute for Biogeochemistry (Jena, Germany) and supported by DIVERSITAS/Future 
EU project BACI [grant ID 640176].

\section{REFERERNCES}

Ågren, G. I. 2008. Stoichiometry and nutrition of plant growth in natural communities. Annual Review of Ecology Evolution \& Systematics 39:153-170.

Agren, G. I., and M. Weih. 2012. Plant stoichiometry at different scales: element concentration patterns reflect environment more than genotype. New Phytologist 194:944-952.

Allen, A. P., and J. F. Gillooly. 2009. Ecology Letters 12:369-384.

Asner, G. P., T. R. Seastedt, and A. R. Townsend. 1997. The decoupling of terrestrial carbon and nitrogen cycles. BioScience 47:226-234.

Carnicer, J., J. Sardans, C. Stefanescu, A. Ubach, M. Bartons, L. Asensio, and J. Peñuelas. 2015. Global biodiversity, stoichiometry and ecosystem function responses to human-induced CNP imbalances. Journal of Plant Physiology 172:82-91.

Chapin III, F. S., G. R. Shaver, and R. A. Kedrowski. 1986. Environmental controls over carbon, nitrogen and phosphorus fractions in Eriophorum Vaginatum in Alaskan Tussock Tundra. Journal of Ecology 74:167-195.

Chen, Y., W. Han, L. Tang, Z. Tang, and J. Fang. 2013. Leaf nitrogen and phosphorus concentrations of woody plants differ in responses to climate, soil and plant growth form. Ecography 36:178-184.

Delgado, M., L. Suriyagoda, A. Zúñiga-Feest, F. Borie, and H. Lambers. 2014. Divergent functioning of Proteaceae species: the South American Embothrium coccineum displays a combination of adaptive traits to survive in high-phosphorus soils. Functional Ecology 28:1356-1366.

Deng, Q., D. Hui, S. Dennis, and K. C. Reddy. 2017. Responses of terrestrial ecosystem phosphorus cycling to nitrogen addition: A meta-analysis. Global Ecology \& Biogeography 26:713-728.

Elser, J. J., W. J. O'Brien, D. R. Dobberfuhl, and T. E. Dowling. 2000. The evolution of ecosystem processes: growth rate and elemental stoichiometry of a key herbivore in temperate and arctic habitats. Journal of Evolutionary Biology 13:845-853.

Elser, J.J., W. F. Fagan, A. J. Kerkhoff, N. G. Swenson, and B. J. Enquist. 2010. Biological stoichiometry of plant production: metabolism, scaling and ecological response to global change. New Phytologist 186:593-608.

Foulds, W. 1993. Nutrient concentrations of foliage and soil in South-Western Australia. New Phytologist 125:529-546.

Fujita, Y., H. O. Venterink, P. M. van Bodegom, J. C. Douma, G. W. Heil, W. Kotowski, T. Okruszko, P. Pawlikowski, P. C. de Ruiter, and M. J. Wassen. 2014. Low investment in sexual reproduction threatens plants adapted to phosphorus limitation. Nature 505:82-86.

Garten, C. T. 1976. Correlations between concentrations of elements in plants. Nature 261:686-688. 
Geng, Y., Z. Wang, C. Liang, J. Fang, F. Baumann, P. Kühn, T. Scholten, and J. S. He. 2012. Effect of geographical range size on plant functional traits and the relationships between plant, soil and climate in Chinese grasslands. Global Ecology and Biogeography 21:416-427.

Guo, Y., X. Yang, C. Schöb, Y. Jiang, and Z. Tang. 2017. Legume shrubs are more nitrogen-homeostatic than non-legume shrubs. Frontiers in Plant Science 8:1662.

Güsewell, S. 2004. N: P ratios in terrestrial plants: variation and functional significance. New Phytologist 164:243-266.

Han, W., J. Fang, D. Guo, and Y. Zhang. 2005. Leaf nitrogen and phosphorus stoichiometry across 753 terrestrial plant species in China. New Phytologist 168:377-385.

Han, W., J. Fang, P. B. Reich, F. Ian Woodward, and Z. Wang. 2011. Biogeography and variability of eleven mineral elements in plant leaves across gradients of climate, soil and plant functional type in China. Ecology Letters 14:788-796.

Hao, Z., Y. Kuang, and M. Kang. 2015. Untangling the influence of phylogeny, soil and climate on leaf element concentrations in a biodiversity hotspot. Functional Ecology 29:165-176.

He, J., L. Wang, D. F. Flynn, X. Wang, W. Ma, and J. Fang. 2008. Leaf nitrogen: phosphorus stoichiometry across Chinese grassland biomes. Oecologia 155:301-310.

He, J., X. Wang, B. Schmid, D. F. B. Flynn, X. Li, P. B. Reich, J. Fang, H. Muraoka, and J. He. 2010. Taxonomic identity, phylogeny, climate and soil fertility as drivers of leaf traits across Chinese grassland biomes. Journal of Plant Research 123:551-561.

Kerkhoff, A. J., W. F. Fagan, J. J. Elser, and B. J. Enquist. 2006. Phylogenetic and growth form variation in the scaling of nitrogen and phosphorus in the seed plants. American Naturalist 168:E103-E122.

Koerselman, W., and A. F. Meuleman. 1996. The vegetation N: P ratio: a new tool to detect the nature of nutrient limitation. Journal of Applied Ecology 33:1441-1450.

Lambers, H., P. L. Clode, H. J. Hawkins, E. Laliberté, R. S. Oliveira, P. Reddell, M. W. Shane, M. Stitt, and P. Weston. 2015. Metabolic adaptations of the non-mycotrophic proteaceae to soils with low phosphorus availability. Annual Plant Reviews 48:289-336.

Lambers, H., and H. Poorter. 1992. Inherent variation in growth rate between higher plants: a search for physiological causes and ecological consequences. Advances in Ecological Research 23:187-261.

Lambers, H., J. A. Raven, G. R. Shaver, and S. E. Smith. 2008. Plant nutrient-acquisition strategies change with soil age. Trends in Ecology \& Evolution 23:95-103.

Mcgroddy, M. E., T. Daufresne, and L. O. Hedin. 2004. Scaling of C:N:P stoichiometry in forests worldwide: implications of terrestrial redfield-type ratios. Ecology 85:2390-2401.

Messier, J., B. J. Mcgill, B. J. Enquist, and M. J. Lechowicz. 2017. Trait variation and integration across scales: is the leaf economic spectrum present at local scales? Ecography 40:685-697. 
Nielsen, S. L., S. Enriquez, C. Duarte, and K. Sand-Jensen. 1996. Scaling maximum growth rates across photosynthetic organisms. Functional Ecology 10:167-175.

Niklas, K. J., and E. D. Cobb. 2005. N, P, and C stoichiometry of Eranthis hyemalis (Ranunculaceae) and the allometry of plant growth. American Journal of Botany 92:1256-1263.

Niklas, K. J., T. Owens, P. B. Reich, and E. D. Cobb. 2005. Nitrogen/phosphorus leaf stoichiometry and the scaling of plant growth. Ecology Letters 8:636-642.

Osnas, J. L., Lichstein, J. W., Reich, P. B., Pacala, S. W. 2013. Global leaf trait relationship: mass, area, and the leaf economics spectrum. Science 340: 741-744.

Page, C. N. 2002. Ecological strategies in fern evolution: a neopteridological overview. Review of Palaeobotany and Palynology 119:1-33.

Penuelas, J., J. Sardans, J. Llusià, S. M. Owen, J. Carnicer, T. W. Giambelluca, E. L. Rezende, M. Waite, and Ü. Niinemets. 2010. Faster returns on 'leaf economics' and different biogeochemical niche in invasive compared with native plant species. Global Change Biology 16:2171-2185.

Price, C. A., I. J. Wright, D. D. Ackerly, Ü. Niinemets, P. B. Reich, and E. J. Veneklaas. 2014. Are leaf functional traits 'invariant'with plant size and what is 'invariance'anyway? Functional Ecology 28:1330-1343.

R Development Core Team. R: A Language and Environment for Statistical Computing. 2018. R Foundation for Statistic Computing, Vienna.

Reich, P. B., and J. Oleksyn. 2004. Global patterns of plant leaf N and P in relation to temperature and latitude. Proceedings of the National Academy of Sciences of the United States of America 101:11001-11006.

Reich, P. B., J. Oleksyn, and I. J. Wright. 2009. Leaf phosphorus influences the photosynthesis-nitrogen relation: a cross-biome analysis of 314 species. Oecologia 160:207-212.

Reich, P. B., J. Oleksyn, I. J. Wright, K. J. Niklas, L. Hedin, and J. J. Elser. 2010. Evidence of a general 2/3-power law of scaling leaf nitrogen to phosphorus among major plant groups and biomes. Proceedings of the Royal Society of London B: Biological Sciences 277:877-883.

Sardans, J., R. Alonso, I. A. Janssens, J. Carnicer, S. Vereseglou, M. C. Rillig, M. Fernández-Martínez, T. G. M. Sanders, and J. Peñuelas. 2016. Foliar and soil concentrations and stoichiometry of nitrogen and phosphorous across European Pinus sylvestris forests: relationships with climate, $\mathrm{N}$ deposition and tree growth. Functional Ecology 30:676-689.

Sardans, J., and J. Peñuelas. 2014. Climate and taxonomy underlie different elemental concentrations and stoichiometries of forest species: the optimum "biogeochemical niche". Plant Ecology 215:441-455.

Sullivan, B. W., S. Alvarez-Clare, S. C. Castle, S. Porder, S. C. Reed, L. Schreeg, A. R. Townsend, and C. C. Cleveland. 2014. Assessing nutrient limitation in complex forested ecosystems: alternatives to 
large-scale fertilization experiments. Ecology 95:668-681.

Tang, Z., W. Xu, G. Zhou, Y. Bai, J. Li, X. Tang, D. Chen, Q. Liu, W. Ma, and G. Xiong. 2018. Patterns of plant carbon, nitrogen, and phosphorus concentration in relation to productivity in China's terrestrial ecosystems. Proceedings of the National Academy of Sciences of the United States of America 115:4033-4038.

Thompson, K., J. A. Parkinson, S. R. Band, and R. E. Spencer. 1997. A comparative study of leaf nutrient concentrations in a regional herbaceous flora. New Phytologist 136:679-689.

Tian, D., Z. Yan, K. J. Niklas, W. Han, J. Kattge, P. B. Reich, Y. Luo, Y. Chen, Z. Tang, and H. Hu. 2018. Global leaf nitrogen and phosphorus stoichiometry and their scaling exponent. National Science Review 5:728-739.

Torrey, J. G. 1978. Nitrogen fixation by actinomycete-nodulated angiosperms. BioScience 28:586-592.

Vitousek, P. M., D. R. Turner, and K. Kitayama. 1995. Foliar nutrients during long-term soil development in Hawaiian montane rain forest. Ecology 76:712-720.

Warton, D. I., I. J. Wright, D. S. Falster, and M. Westoby. 2006. Bivariate line-fitting methods for allometry. Biological Reviews 81:259-291.

Watanabe, T., M. R. Broadley, S. Jansen, P. J. White, J. Takada, K. Satake, T. Takamatsu, S. J. Tuah, and M. Osaki. 2007. Evolutionary control of leaf element composition in plants. New Phytologist 174:516523.

White, P. J., M. R. Broadley, J. A. Thompson, J. W. Mcnicol, M. J. Crawley, P. R. Poulton, and A. E. Johnston. 2012. Testing the distinctness of shoot ionomes of angiosperm families using the Rothamsted Park Grass Continuous Hay Experiment. New Phytologist 196:101-109.

Wright, I. J., P. Reich, and M. Westoby. 2001. Strategy shifts in leaf physiology, structure and nutrient content between species of high-and low-rainfall and high-and low-nutrient habitats. Functional Ecology 15:423-434.

Wright, I. J., P. B. Reich, J. H. C. Cornelissen, D. S. Falster, E. Garnier, K. Hikosaka, B. B. Lamont, W. Lee, J. Oleksyn, and N. Osada. 2005. Assessing the generality of global leaf trait relationships. New Phytologist 166:485-496.

Wright, I. J., P. B. Reich, M. Westoby, D. D. Ackerly, Z. Baruch, F. Bongers, J. Cavender-Bares, T. Chapin, J. H. Cornelissen, and M. Diemer. 2004. The worldwide leaf economics spectrum. Nature 428:821827.

Yan, Z., D. Tian, W. Han, Z. Tang, and J. Fang. 2017. An assessment on the uncertainty of the nitrogen to phosphorus ratio as a threshold for nutrient limitation in plants. Annals of Botany 120:937-942.

Yang, X., X. Chi, C. Ji, H. Liu, W. Ma, A. Mohhammat, Z. Shi, X. Wang, S. Yu, and M. Yue. 2016. Variations of leaf $\mathrm{N}$ and $\mathrm{P}$ concentrations in shrubland biomes across northern China: phylogeny, 
climate and soil. Biogeosciences 13:4429-4438.

547 Yang, X., Z. Huang, K. Zhang, and J. H. Cornelissen. 2015. C: N: P stoichiometry of Artemisia species and 548 close relatives across northern China: unravelling effects of climate, soil and taxonomy. Journal of 549 Ecology 103:1020-1031.

550 Yang, X., Z. Huang, K. Zhang, and J. H. C. Cornelissen. 2017. Taxonomic effect on plant base

551 concentrations and stoichiometry at the tips of the phylogeny prevails over environmental effect along 552 a large scale gradient. Oikos 126:1241-1249.

553 Yu, Q., Q. Chen, J. J. Elser, N. He, H. Wu, S. Zhang, J. Wu, Y. Bai, and X. Han. 2010. Stoichiometric 554 homeostasis underlies ecosystem structure, functioning and stability. Ecology Letters 13:1390-1399.

555 Yu, Q., K. Wilcox, K. L. Pierre, A. K. Knapp, X. Han, and M. D. Smith. 2015. Stoichiometric homeostasis 556 predicts plant species dominance, temporal stability, and responses to global change. Ecology 557 96:2328-2335.

558 Zhang, J., N. Zhao, C. Liu, H. Yang, M. Li, G. Yu, K. Wilcox, Q. Yu, and N. He. 2018. C:N:P stoichiometry 559 in China's forests: from organs to ecosystems. Functional Ecology 32:50-60.

560 Zhang, S. B., J. L. Zhang, J. Slik, and K. F. Cao. 2012. Leaf element concentrations of terrestrial plants 561 across China are influenced by taxonomy and the environment. Global Ecology and Biogeography $562 \quad 21: 809-818$.

Zhao, N., G. Yu, N. He, F. Xia, Q. Wang, R. Wang, Z. Xu, and Y. Jia. 2016. Invariant allometric scaling of 564 nitrogen and phosphorus in leaves, stems, and fine roots of woody plants along an altitudinal gradient. Journal of Plant Research 129:647-657. 
566 Table 1. Leaf $\mathrm{N}$ and P stoichiometry of 62 families in our study. $n$ represents the sample size of 567 each family.

\begin{tabular}{|c|c|c|c|c|c|c|c|}
\hline \multirow[b]{2}{*}{ Family } & \multirow[b]{2}{*}{$n$} & \multicolumn{2}{|c|}{$\mathrm{N}\left(\mathrm{mg} \mathrm{g}^{-1}\right)$} & \multicolumn{2}{|c|}{$\mathrm{P}\left(\mathrm{mg} \mathrm{g}^{-1}\right)$} & \multicolumn{2}{|c|}{$\mathrm{N}: \mathrm{P}$} \\
\hline & & $\begin{array}{l}\text { Geometric } \\
\text { mean }\end{array}$ & $\mathrm{SE}$ & $\begin{array}{c}\text { Geometric } \\
\text { mean }\end{array}$ & $\mathrm{SE}$ & $\begin{array}{c}\text { Geometric } \\
\text { mean }\end{array}$ & SE \\
\hline Aceraceae & 94 & 22.45 & 0.54 & 1.86 & 0.07 & 12.06 & 0.42 \\
\hline Anacardiaceae & 107 & 16.59 & 0.61 & 1.21 & 0.06 & 13.76 & 0.53 \\
\hline Annonaceae & 56 & 21.32 & 0.69 & 1.00 & 0.06 & 21.29 & 1.29 \\
\hline Apocynaceae & 38 & 20.01 & 0.95 & 1.12 & 0.09 & 17.85 & 1.22 \\
\hline Aquifoliaceae & 64 & 15.12 & 0.43 & 0.70 & 0.03 & 21.55 & 0.83 \\
\hline Araliaceae & 79 & 21.92 & 1.01 & 1.64 & 0.10 & 13.34 & 0.48 \\
\hline Berberidaceae & 43 & 18.34 & 0.79 & 1.24 & 0.08 & 14.78 & 1.03 \\
\hline Betulaceae & 323 & 22.50 & 0.33 & 1.67 & 0.04 & 13.48 & 0.29 \\
\hline Burseraceae & 70 & 16.45 & 0.42 & 0.72 & 0.03 & 23.02 & 1.08 \\
\hline Caprifoliaceae & 237 & 19.36 & 0.48 & 1.45 & 0.04 & 13.37 & 0.33 \\
\hline Caryophyllaceae & 35 & 21.00 & 1.17 & 1.69 & 0.19 & 12.46 & 1.55 \\
\hline Celastraceae & 131 & 22.57 & 0.60 & 1.54 & 0.06 & 14.65 & 0.46 \\
\hline Chenopodiaceae & 173 & 23.44 & 0.66 & 1.48 & 0.07 & 16.04 & 0.71 \\
\hline Compositae & 1061 & 16.88 & 0.21 & 1.45 & 0.03 & 11.60 & 0.19 \\
\hline Coriariaceae & 37 & 14.84 & 1.24 & 1.10 & 0.07 & 13.46 & 1.24 \\
\hline Cupressaceae & 62 & 10.89 & 0.37 & 1.04 & 0.06 & 10.49 & 0.52 \\
\hline Cyperaceae & 314 & 18.67 & 0.36 & 1.30 & 0.04 & 14.45 & 0.40 \\
\hline Elaeagnaceae & 42 & 30.30 & 1.05 & 1.51 & 0.13 & 20.01 & 1.30 \\
\hline Ericaceae & 499 & 14.32 & 0.19 & 0.98 & 0.02 & 14.63 & 0.27 \\
\hline Eucommiaceae & 157 & 20.18 & 0.60 & 1.18 & 0.05 & 17.34 & 0.74 \\
\hline Euphorbiaceae & 54 & 16.82 & 0.82 & 1.31 & 0.10 & 12.87 & 0.87 \\
\hline Fagaceae & 480 & 17.89 & 0.24 & 1.06 & 0.02 & 16.96 & 0.32 \\
\hline Gleicheniaceae & 57 & 10.08 & 0.40 & 0.43 & 0.03 & 23.38 & 1.44 \\
\hline Gramineae & 1019 & 18.53 & 0.23 & 1.35 & 0.03 & 13.74 & 0.23 \\
\hline Guttiferae & 35 & 15.04 & 0.92 & 0.88 & 0.08 & 17.03 & 1.42 \\
\hline Hamamelidaceae & 98 & 13.95 & 0.33 & 0.89 & 0.03 & 15.70 & 0.53 \\
\hline Juglandaceae & 64 & 19.44 & 0.88 & 1.23 & 0.10 & 15.81 & 0.93 \\
\hline Labiatae & 111 & 21.87 & 0.70 & 1.80 & 0.08 & 12.15 & 0.49 \\
\hline Lauraceae & 163 & 18.49 & 0.49 & 0.90 & 0.03 & 20.49 & 0.74 \\
\hline Lecythidaceae & 81 & 20.51 & 0.54 & 0.64 & 0.02 & 31.83 & 1.10 \\
\hline Leguminosae & 1122 & 27.04 & 0.29 & 1.20 & 0.02 & 22.57 & 0.27 \\
\hline Liliaceae & 75 & 24.40 & 1.18 & 1.81 & 0.12 & 13.47 & 0.65 \\
\hline Melastomataceae & 82 & 14.87 & 0.52 & 0.66 & 0.03 & 22.44 & 0.74 \\
\hline Meliaceae & 35 & 19.51 & 0.97 & 1.48 & 0.14 & 13.15 & 1.11 \\
\hline Moraceae & 145 & 22.64 & 0.72 & 1.19 & 0.06 & 19.01 & 1.68 \\
\hline Myricaceae & 41 & 16.82 & 0.29 & 0.48 & 0.03 & 35.40 & 1.73 \\
\hline Myrsinaceae & 79 & 14.81 & 0.50 & 0.71 & 0.04 & 20.73 & 1.14 \\
\hline Myrtaceae & 222 & 10.81 & 0.19 & 0.55 & 0.02 & 19.75 & 0.43 \\
\hline
\end{tabular}




\begin{tabular}{lccccccc}
\hline Oleaceae & 147 & 21.42 & 0.54 & 1.39 & 0.06 & 15.38 & 0.55 \\
Pinaceae & 301 & 13.52 & 0.21 & 1.24 & 0.04 & 10.91 & 0.29 \\
Plantaginaceae & 50 & 16.79 & 0.92 & 1.53 & 0.16 & 10.95 & 0.88 \\
Polygonaceae & 97 & 28.09 & 1.01 & 1.98 & 0.14 & 14.22 & 0.80 \\
Primulaceae & 50 & 18.36 & 1.07 & 1.46 & 0.13 & 12.70 & 0.81 \\
Proteaceae & 198 & 6.11 & 0.16 & 0.27 & 0.01 & 22.53 & 0.63 \\
Ranunculaceae & 66 & 25.35 & 0.84 & 1.95 & 0.14 & 13.03 & 0.96 \\
Rhamnaceae & 162 & 21.90 & 0.52 & 1.19 & 0.04 & 18.42 & 0.50 \\
Rosaceae & 1008 & 19.26 & 0.19 & 1.47 & 0.02 & 13.12 & 0.19 \\
Rubiaceae & 209 & 17.83 & 0.43 & 0.86 & 0.03 & 20.83 & 0.74 \\
Rutaceae & 107 & 23.18 & 0.66 & 1.21 & 0.07 & 19.11 & 0.86 \\
Salicaceae & 312 & 21.57 & 0.41 & 1.80 & 0.05 & 11.97 & 0.30 \\
Sapindaceae & 46 & 18.76 & 0.71 & 1.28 & 0.10 & 14.68 & 1.03 \\
Sapotaceae & 78 & 15.23 & 0.62 & 0.65 & 0.03 & 23.58 & 1.27 \\
Saxifragaceae & 161 & 21.75 & 0.51 & 1.69 & 0.07 & 12.91 & 0.50 \\
Scrophulariaceae & 50 & 20.42 & 0.65 & 1.59 & 0.13 & 12.87 & 1.08 \\
Symplocaceae & 58 & 14.72 & 0.36 & 0.66 & 0.03 & 22.21 & 0.90 \\
Tamaricaceae & 67 & 18.66 & 1.20 & 0.88 & 0.06 & 21.32 & 0.98 \\
Theaceae & 175 & 13.10 & 0.32 & 0.68 & 0.02 & 19.29 & 0.56 \\
Tiliaceae & 67 & 24.95 & 0.85 & 1.83 & 0.07 & 13.61 & 0.60 \\
Ulmaceae & 133 & 23.93 & 0.53 & 1.52 & 0.06 & 15.74 & 0.59 \\
Umbelliferae & 57 & 24.40 & 0.90 & 2.12 & 0.16 & 11.50 & 0.81 \\
Verbenaceae & 203 & 21.17 & 0.52 & 1.31 & 0.03 & 16.12 & 0.44 \\
Zygophyllaceae & 60 & 29.40 & 1.37 & 1.42 & 0.08 & 20.69 & 0.82 \\
\hline & & & & & & &
\end{tabular}


569 Table 2. Exponents of reduced major axis (RMA) regression between leaf $\mathrm{N}$ and leaf $\mathrm{P}$

570 concentrations of 54 families, e.g. $\log _{10}$ leaf $\mathrm{N}=\alpha \log _{10}$ leaf $\mathrm{P}+\log _{10} \beta$, and the comparisons

571 with $2 / 3$ and $3 / 4$, respectively. " $\checkmark$ " indicates that the exponent of leaf $N$ vs. leaf $P$ scaling is

572 not statistically significantly different from $2 / 3$ or $3 / 4$; " $\times$ " indicates that the exponents of leaf

$573 \mathrm{~N}$ vs. leaf $\mathrm{P}$ scaling are lower or higher than $2 / 3$ or $3 / 4$, respectively. The $p$ values are

574 summarized from a likelihood ratios test.

\begin{tabular}{|c|c|c|c|c|c|}
\hline \multirow{2}{*}{ Family } & \multirow{2}{*}{$\alpha_{\text {RMA }}(95 \%$ CI $)$} & \multicolumn{2}{|c|}{ Compare with $2 / 3$} & \multicolumn{2}{|c|}{ Compare with $3 / 4$} \\
\hline & & $2 / 3$ & $p$ & $3 / 4$ & $p$ \\
\hline Aceraceae & $0.631(0.525,0.759)$ & $\sqrt{ }$ & 0.559 & $\sqrt{ }$ & 0.067 \\
\hline Anacardiaceae & $0.756(0.650,0.880)$ & $\sqrt{ }$ & 0.104 & $\sqrt{ }$ & 0.919 \\
\hline Apocynaceae & $0.594(0.447,0.789)$ & $\sqrt{ }$ & 0.418 & $\sqrt{ }$ & 0.105 \\
\hline Aquifoliaceae & $0.683(0.545,0.857)$ & $\sqrt{ }$ & 0.812 & $\sqrt{ }$ & 0.417 \\
\hline Araliaceae & $0.777(0.676,0.891)$ & $x$ & 0.031 & $\sqrt{ }$ & 0.619 \\
\hline Betulaceae & $0.656(0.592,0.727)$ & $\sqrt{ }$ & 0.823 & $\times$ & 0.013 \\
\hline Caprifoliaceae & $0.859(0.775,0.953)$ & $\times$ & $<0.001$ & $\times$ & 0.010 \\
\hline Celastraceae & $0.640(0.561,0.730)$ & $\sqrt{ }$ & 0.534 & $\times$ & 0.018 \\
\hline Chenopodiaceae & $0.594(0.515,0.684)$ & $\sqrt{ }$ & 0.106 & $x$ & 0.001 \\
\hline Compositae & $0.628(0.597,0.660)$ & $\times$ & $<0.001$ & $x$ & $<0.001$ \\
\hline Cupressaceae & $0.576(0.464,0.716)$ & $\sqrt{ }$ & 0.187 & $\times$ & 0.018 \\
\hline Cyperaceae & $0.596(0.542,0.656)$ & $\times$ & 0.022 & $x$ & $<0.001$ \\
\hline Elaeagnaceae & $0.420(0.331,0.531)$ & $\times$ & 0.003 & $\times$ & $<0.001$ \\
\hline Ericaceae & $0.581(0.541,0.623)$ & $x$ & $<0.001$ & $x$ & $<0.001$ \\
\hline Eucommiaceae & $0.752(0.644,0.879)$ & $\sqrt{ }$ & 0.127 & $\sqrt{ }$ & 0.969 \\
\hline Euphorbiaceae & $0.619(0.488,0.784)$ & $\sqrt{ }$ & 0.531 & $\sqrt{ }$ & 0.109 \\
\hline Fagaceae & $0.649(0.598,0.704)$ & $\sqrt{ }$ & 0.523 & $x$ & $<0.001$ \\
\hline Gleicheniaceae & $0.650(0.505,0.837)$ & $\sqrt{ }$ & 0.859 & $\sqrt{ }$ & 0.277 \\
\hline Gramineae & $0.666(0.630,0.703)$ & $\sqrt{ }$ & 0.952 & $\times$ & $<0.001$ \\
\hline Guttiferae & $0.663(0.487,0.902)$ & $\sqrt{ }$ & 0.969 & $\sqrt{ }$ & 0.426 \\
\hline Hamamelidaceae & $0.666(0.554,0.801)$ & $\sqrt{ }$ & 0.992 & $\sqrt{ }$ & 0.206 \\
\hline Juglandaceae & $0.574(0.476,0.692)$ & $\sqrt{ }$ & 0.115 & $\times$ & 0.006 \\
\hline Labiatae & $0.679(0.578,0.797)$ & $\sqrt{ }$ & 0.826 & $\sqrt{ }$ & 0.221 \\
\hline Lauraceae & $0.724(0.627,0.834)$ & $\sqrt{ }$ & 0.260 & $\sqrt{ }$ & 0.620 \\
\hline Lecythidaceae & $0.836(0.676,1.034)$ & $x$ & 0.038 & $\sqrt{ }$ & 0.318 \\
\hline Leguminosae & $0.689(0.658,0.721)$ & $\sqrt{ }$ & 0.169 & $x$ & $<0.001$ \\
\hline Liliaceae & $0.762(0.639,0.908)$ & $\sqrt{ }$ & 0.135 & $\sqrt{ }$ & 0.860 \\
\hline Melastomataceae & $0.768(0.656,0.898)$ & $\sqrt{ }$ & 0.063 & $\sqrt{ }$ & 0.694 \\
\hline Meliaceae & $0.527(0.386,0.718)$ & $\sqrt{ }$ & 0.134 & $\times$ & 0.026 \\
\hline Moraceae & $0.688(0.607,0.781)$ & $\sqrt{ }$ & 0.621 & $\sqrt{ }$ & 0.181 \\
\hline Myricaceae & $0.307(0.233,0.404)$ & $\times$ & $<0.001$ & $\times$ & $<0.001$ \\
\hline Myrsinaceae & $0.641(0.516,0.797)$ & $\sqrt{ }$ & 0.725 & $\sqrt{ }$ & 0.157 \\
\hline Myrtaceae & $0.609(0.550,0.675)$ & $\sqrt{ }$ & 0.087 & $\times$ & $<0.001$ \\
\hline Oleaceae & $0.621(0.539,0.716)$ & $\sqrt{ }$ & 0.368 & $\times$ & 0.012 \\
\hline
\end{tabular}




\begin{tabular}{lllclc}
\hline Pinaceae & $0.507(0.459,0.559)$ & $\times$ & $<0.001$ & $\times$ & $<0.001$ \\
Plantaginaceae & $0.536(0.427,0.672)$ & $\sqrt{ }$ & 0.058 & $\times$ & $<0.001$ \\
Polygonaceae & $0.509(0.434,0.597)$ & $\times$ & 0.001 & $\times$ & $<0.001$ \\
Primulaceae & $0.673(0.544,0.731)$ & $\sqrt{ }$ & 0.934 & $\sqrt{ }$ & 0.309 \\
Proteaceae & $0.770(0.687,0.862)$ & $\times$ & 0.014 & $\sqrt{ }$ & 0.655 \\
Rhamnaceae & $0.711(0.628,0.805)$ & $\sqrt{ }$ & 0.307 & $\sqrt{ }$ & 0.410 \\
Rosaceae & $0.613(0.580,0.648)$ & $\times$ & 0.003 & $\times$ & $<0.001$ \\
Rubiaceae & $0.599(0.532,0.676)$ & $\sqrt{ }$ & 0.081 & $\times$ & $<0.001$ \\
Rutaceae & $0.527(0.450,0.618)$ & $\times$ & 0.004 & $\times$ & $<0.001$ \\
Salicaceae & $0.738(0.666,0.817)$ & $\times$ & 0.052 & $\sqrt{ }$ & 0.749 \\
Sapindaceae & $0.491(0.374,0.644)$ & $\times$ & 0.028 & $\times$ & 0.003 \\
Saxifragaceae & $0.533(0.465,0.611)$ & $\times$ & 0.001 & $\times$ & $<0.001$ \\
Symplocaceae & $0.575(0.448,0.737)$ & $\sqrt{ }$ & 0.241 & $\times$ & 0.036 \\
Tamaricaceae & $0.991(0.841,1.167)$ & $\times$ & $<0.001$ & $\times$ & 0.001 \\
Theaceae & $0.846(0.740,0.967)$ & $\times$ & $<0.001$ & $\sqrt{ }$ & 0.084 \\
Tiliaceae & $0.875(0.691,1.108)$ & $\times$ & 0.024 & $\sqrt{ }$ & 0.199 \\
Ulmaceae & $0.578(0.492,0.680)$ & $\sqrt{ }$ & 0.083 & $\times$ & 0.002 \\
Umbelliferae & $0.487(0.381,0.622)$ & $\times$ & $<0.001$ & $\times$ & 0.001 \\
Verbenaceae & $0.949(0.837,1.076)$ & $\times$ & $<0.001$ & $\times$ & $<0.001$ \\
Zygophyllaceae & $0.859(0.713,1.035)$ & $\times$ & 0.008 & $\sqrt{ }$ & 0.147 \\
\hline
\end{tabular}


576 Figure 1. Relationships between leaf $\mathrm{N}$ and P stoichiometry on family-level and MAT and MAP, 577 respectively. (a) leaf $\mathrm{N}$ concentration against MAT; (b) leaf P concentration against MAT; (c) 578 leaf N:P ratios against MAT; (d) leaf N against MAP; (e) leaf P against MAP; (f) leaf N:P ratios 579 against MAP. Note: each color indicates a family. Each data point denotes an individual record. 580 The solid lines indicate significant correlations with $p<0.05$. MAT, mean annual temperature. 581 MAP, mean annual precipitation.

582
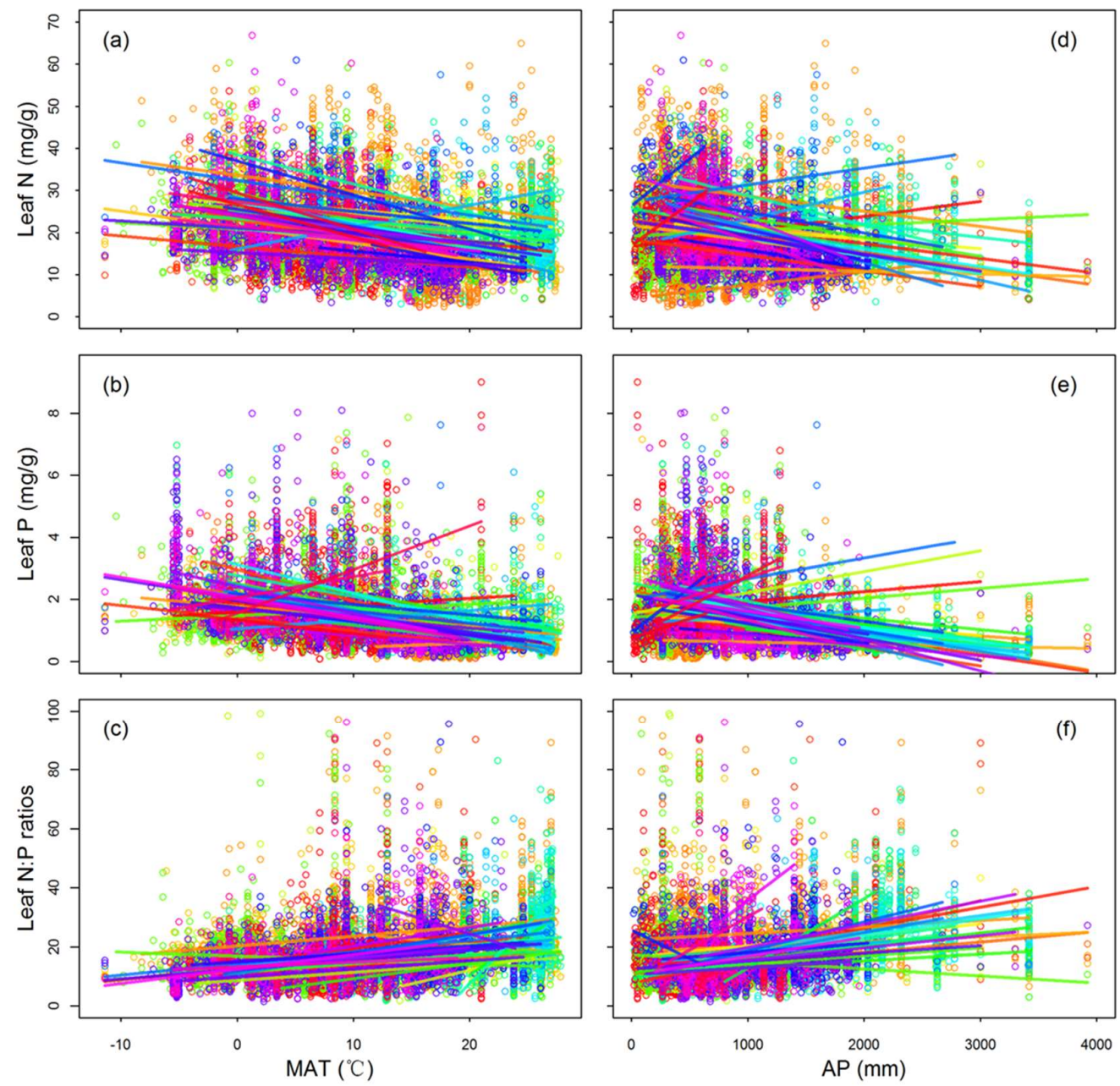
583 Figure 2. The leaf $\mathrm{N}$ and leaf $\mathrm{P}$ scaling relationships of 54 families from our dataset. (a)

584 Frequency distribution of the scaling exponents of 54 families; (b) Relationships between leaf

$585 \mathrm{~N}$ and leaf $\mathrm{P}$ concentrations of each family. The solid line in each color in (b) indicate the

586 significant leaf $\mathrm{N} \sim \mathrm{P}$ scaling relationship on family-level with $p<0.05$. Scaling exponents were

587 calculated from the RMA regression between leaf $\mathrm{N}$ and leaf $\mathrm{P}$ concentrations. e.g., $\log 10$ leaf

$588 \mathrm{~N}=\alpha \log 10$ leaf $\mathrm{P}+\log 10 \beta$.

589
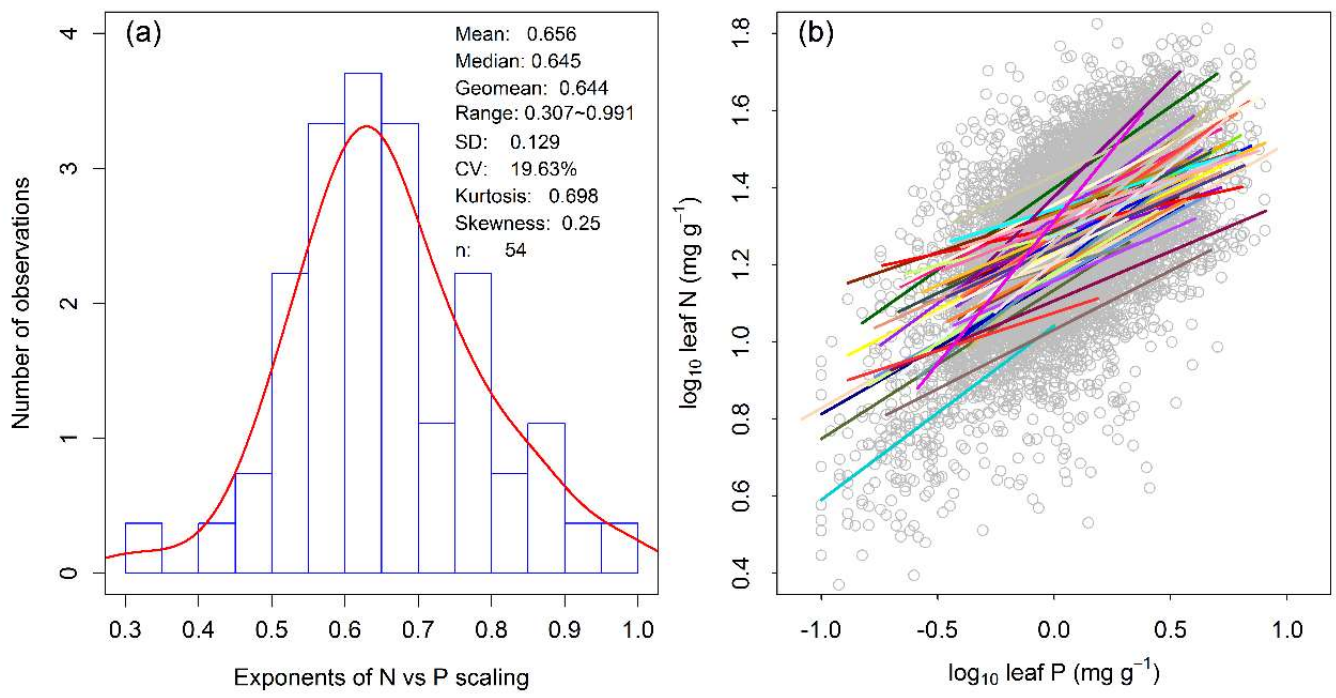


\section{SUPPORTING INFORMATION}

Table S1. The statistics including geometric means, ranges, coefficient of variance (CV), standard error (SE) of leaf $\mathrm{N}$ and $\mathrm{P}$ concentrations, $\mathrm{N}: \mathrm{P}$ ratios and $\mathrm{N} \sim \mathrm{P}$ scaling relationships based on the randomly sampled records using Monte Carlo methods.

Table S2. The statistics of leaf $\mathrm{N}$ and P scaling exponents calculated from the randomly sampled records using Monte Carlo methods by the RMA regression between leaf $\mathrm{N}$ and leaf $\mathrm{P}$ concentrations, e.g., $\log 10$ leaf $\mathrm{N}=\alpha \log 10$ leaf $\mathrm{P}+\log 10 \beta$, including $p$-values, $r^{2}, 95 \% \mathrm{CI}$ of the slopes and constants. Each regression relationships were statistically significant with $p<0.05$. NA represents nonsignificant relationships with $p>0.05$.

Table S3. The ranges of 62 families' distributions including ranges of latitude, MAT and MAP, and the regression analysis results of leaf $\mathrm{N}$ and $\mathrm{P}$ concentrations and $\mathrm{N}: \mathrm{P}$ ratios against MAT and MAP. Each regression relationships were statistically significant with $p<0.05$. NA represents nonsignificant relationships with $p>0.05$.

Figure S1. Leaf N and P concentrations of different sampling sizes by Monte Carlo Sampling. (a) and (b) indicate leaf $\mathrm{N}$ concentration from 0 to 100 and 100 to 10000 , respectively. (c) and (d) indicate leaf $\mathrm{P}$ concentration from 0 to 100 and 100 to 10000 , respectively. The geometric mean values of leaf $\mathrm{N}$ and $\mathrm{P}$ concentrations were showed.

Figure S2. Leaf N and P ratios and N P scaling exponents of different sampling sizes by Monte Carlo Sampling. (a) and (b) indicate leaf N:P ratios from 0 to 100 and 100 to 10000, respectively. (c) and (d) indicate leaf $\mathrm{N} \sim \mathrm{P}$ scaling exponents from 0 to 100 and 100 to 10000 , respectively. Reduced major axis (RMA) regression was used to determine the $\mathrm{N}$ vs. P scaling relationship. The geometric mean values of leaf N:P ratios and leaf N P scaling exponents were showed.

Figure S3. Statistics of N P scaling exponents of different sampling sizes by Monte Carlo Sampling. (a) shows the numbers of significant $N \sim P$ scaling (with $p<0.05$ ) in each 1000 runs during sampling of different sample sizes; (b) indicates the CVs of N P scaling exponents of in each 1000 runs during sampling of different sample sizes. Reduced major axis (RMA) regression was used to determine the $\mathrm{N}$ vs. P scaling relationship.

Figure S4. Relationships between family-level N vs P scaling exponent and (a) the specific 
624 sample size of a family; and (b) number of species within a family. The red dashed line 625 represents the empirical values of $2 / 3$. 
Figure S1.
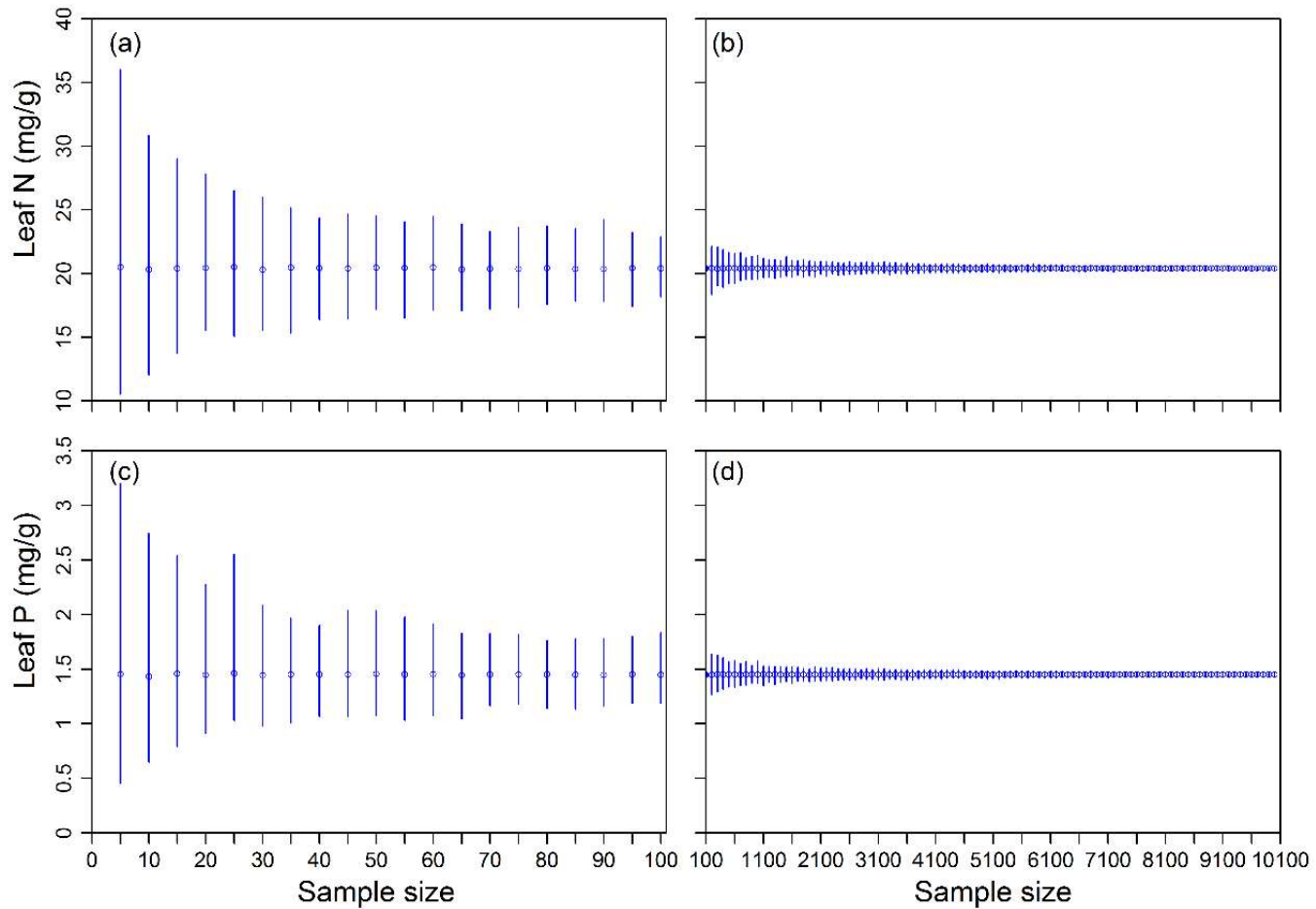
Figure S2.
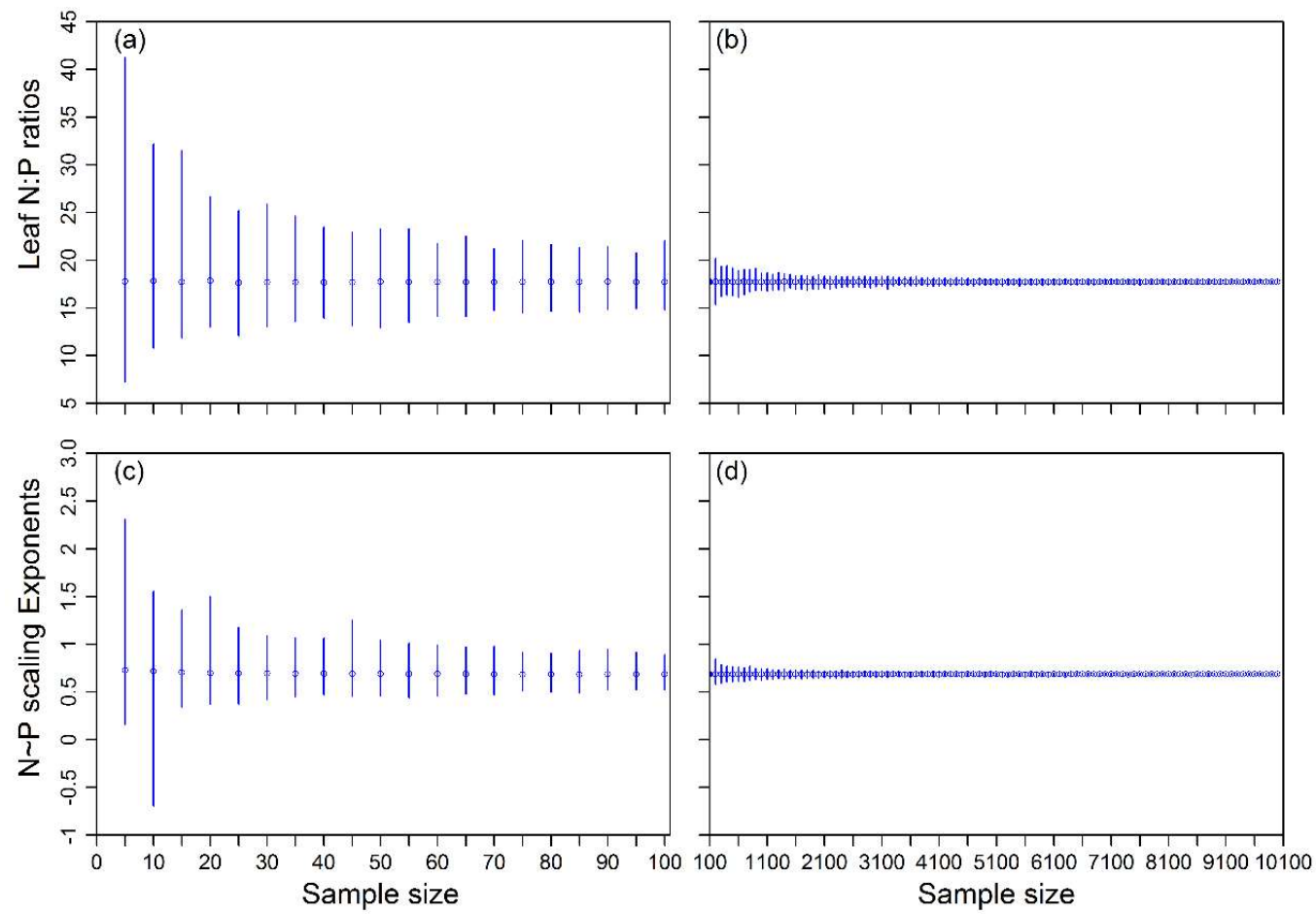

628 
Figure S3.
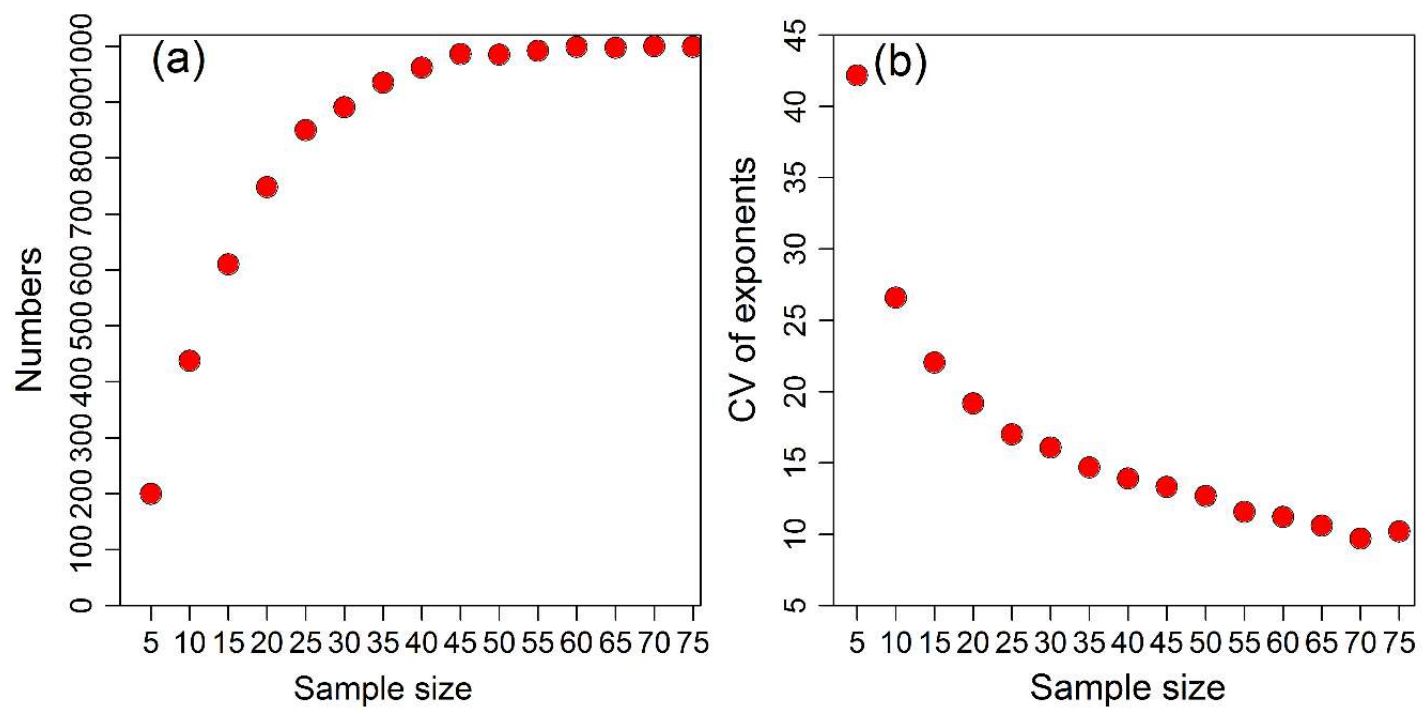
Figure S4
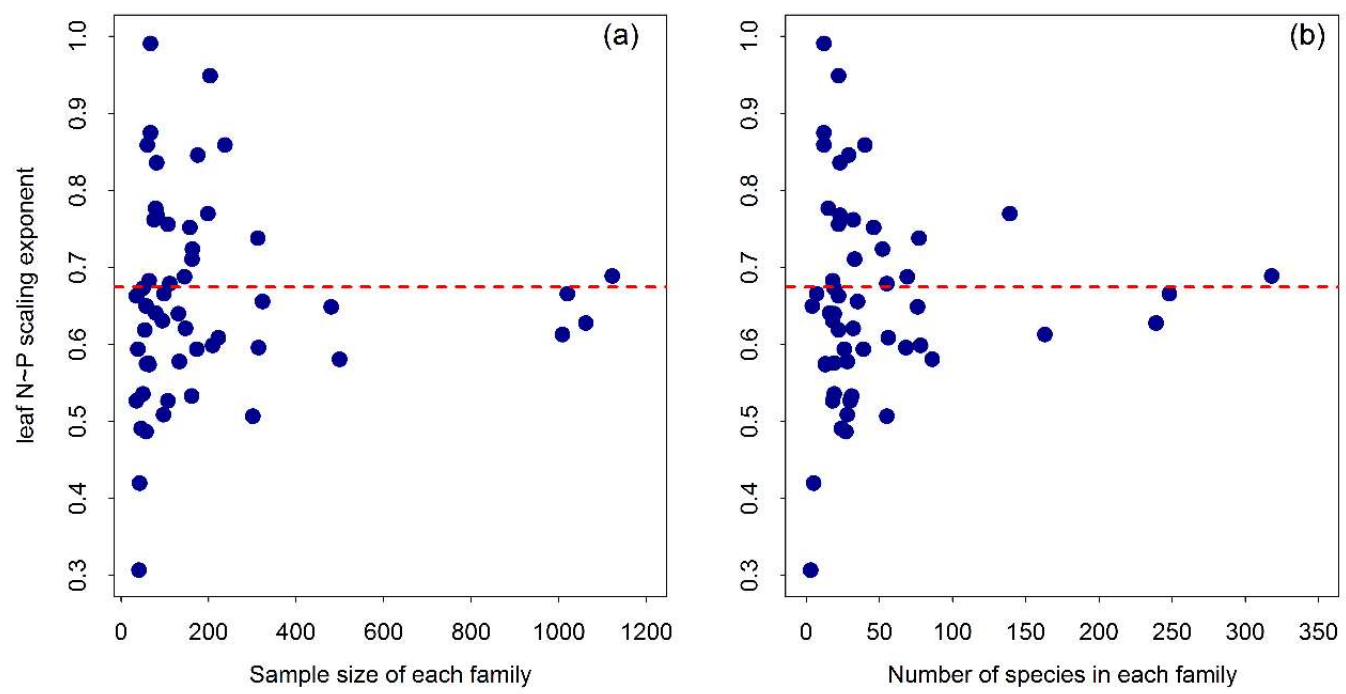